\title{
Genetic resources of Durum wheat in Russia on the content of yellow pigment in grain
}

\author{
Malchikov P.N.*, Myasnikova M.G. \\ Samara Research Scientific Institute of Agriculture, Bezenchuk, Samara region, Russia \\ *e-mail:sagrs-mal@mail.ru
}

The content of yellow pigments in the grain, along with the quantity and quality of gluten, is one of the important components of grain quality in world markets. According to experts, this trait determines the general quality level of durum wheat grains by $20 \%$. In the process of breedings exists unceasing increase the yellow pigment content in grain, straight and pasta from durum wheat. In Russia, this direction of breeding has been developing most intensively since the creation of the Saratovskaya zolotistaya cultivar. Obviously, the accumulation of transgressions is associated with changes in the composition and activity of the system of genes of complex and multistage biosynthesis pigment content and oxidative enzymes. In process of the breedings for this trait based on the genetic system of Saratovskaya zolotistaya in Agricultural scientific institute of Samara region are received transgressions, exceeding level of the initial cultivars on $12.5 \%$ (Pamayati Chehovicha), 14.2 \% (Bezenchukskaya krepost), $20.6 \%$ (1429d-10), 28.4 \% (Bezenchukskaya zolotistaya). Some commercial cultivars (Bezenchukskaya steppe, Bezenchukskaya 210, Bezenchukskaya 205, Bezenchukskaya niva, Elizavetinskaya) has contents of the yellow pigment at a rate of Saratovskaya zolotistaya. The cultivar Bezenchukskaya zolotistaya in the conditions of the Middle Volga region is the absolute record among the studied genotypes of Russian and foreign breeding (Australia, Austria, Germany, Italy, Kazakhstan, Canada, USA, CIMMYT). The Accumulation of the pigment in grain of this cultivar reaches $9 \mathrm{mg} / \mathrm{kg}$. In the process of studying cultivars and breeding lines, genotypes were identified that exceed the Saratovskaya zolotistaya in value trait: Gordeiforme 677, Gordeiforme 878, Gordeiforme 879 (Altai Agricultural scientific institute), 2012d-6, 1981d-12 (Samara Agricultural scientific institute), Duroflaus (Austria), Hyperno, Tjikuri (Australia). The Coefficient heritabilty trait in broad sense of the word $\left(\mathrm{H}^{2}\right)$ has amounted to 0.52, genotype - environment interactions were of low. The Defining influence genotype in variation of the trat suggests high efficiency to breedings on base of the genetic systems studied cultivars. 